\title{
Randomised controlled trial: comparison of colloid or crystalloid for partial exchange transfusion for treatment of neonatal polycythaemia
}

\author{
W Wong, T F Fok, C H Lee, P C Ng, K W So, Y Ou, K L Cheung
}

\begin{abstract}
Aim-To compare the efficacy of using isotonic saline (crystalloid) or $\mathbf{5 \%}$ albumin (colloid) as replacement fluid in partial exchange transfusion (PET) for the treatment of neonatal polycythaemia.

Methods-One hundred and two polycythaemic full term infants were randomly allocated to receive PET with either isotonic saline or $5 \%$ albumin. The criteria for PET were: (a) venous haematocrit $\geqslant$ 0.7 ; or (b) venous haematocrit $0.65-0.69$ with symptoms or signs attributable to polycythaemia.

Results-PET with either saline $(n=53)$ or $5 \%$ albumin $(n=50)$ resulted in a significant and sustained decline in haematocrit up to 24 hours after PET. Although the immediate haemodilution effect of isotonic saline was statistically smaller than that of $5 \%$ albumin (decline in haematocrit $19.3 \%$ vs $22.8 \%$ of pre-PET value), the difference was too small to be of any clinical significance, and the haematocrit at 4 or 24 hours after PET did not differ significantly between the two groups. PET with either replacement fluid was not associated with any complication. The serum sodium and potassium concentrations were not significantly affected by the PET in either group.

Conclusions-Both isotonic saline and 5\% albumin are effective when used as replacement fluid in PET for the treatment of neonatal polycythaemia. Isotonic saline, which is cheaper and free of infection, should be the replacement fluid of choice.

(Arch Dis Child 1997;77:F115-F118)
\end{abstract}

Department of

Paediatrics

Prince of Wales

Hospital

Shatin

Hong Kong

People's Republic of

China

W Wong

T F Fok

$\mathrm{C}$ H Lee

$\mathrm{PC} \mathrm{Ng}$

$\mathrm{KW}$ So

$\mathrm{YOu}$

K L Cheung

Correspondence to: Dr William Wong.

Accepted 18 March 1997

Accepted 18 March 1997

Neonatal polycythaemia, which occurs in up to $5 \%$ of term neonates, ${ }^{1}$ is associated with increased blood viscosity and hence reduction in tissue perfusion and hypoxia. Complications resulting from cardiorespiratory, gastrointestinal, renal and neurological compromise can occur. Long term neurological damage has also been reported in polycythaemic infants who were asymptomatic during the neonatal period. ${ }^{2}$ The condition is customarily treated with partial exchange transfusion (PET), to reduce haematocrit and blood viscosity while maintaining circulatory volume. Replacement fluids used in PET could be a colloid solution, such as plasma protein fraction or fresh frozen plasma, or a crystalloid solution, such as isotonic saline or Ringer's solution. Compared with colloids, crystalloid solutions are cheaper and do not carry any risk of infection, and should theoretically be the replacement fluid of choice, provided that their therapeutic efficacy is comparable. Before we conducted our study no randomised controlled trial had compared colloids with crystalloids. Since then one study by Roithmaier et al has been published. ${ }^{3}$ This compared the efficacy of Ringer's solution (crystalloid) with a serum preparation (colloid), showing no significant difference in the reduction of haematocrit in polycythaemic neonates.

\section{Methods}

All term infants admitted into the neonatal unit, Prince of Wales Hospital, during January 1995 to May 1996 were recruited into the study if they required PET for the treatment of polycythaemia diagnosed within 6 hours of birth. The criteria for PET were: (1) venous haematocrit $\geqslant 0.7$; (2) venous haematocrit 0.65-0.69 with symptoms or signs attributable to polycythaemia-respiratory distress, apnoea, cyanosis, lethargy, irritability, tremors, abnormal cry, hypotonia, seizures, impaired peripheral circulation (defined as skin capillary refilling time $>4$ seconds), and hypoglycaemia. Infants with lethal congenital malformations or suspected sepsis were excluded. The infants were randomly allocated by computer to receive PET with either isotonic saline $(0.9 \%$ $\mathrm{NaCl}$ ) or $5 \%$ albumin (Plasma Protein Fraction (Human) USP Plasmatein, Alpha Therapeutic Corporation, Los Angeles, USA). The blood volume for PET (V) was calculated from the initial haematocrit of the patients and the desired haematocrit of $55 \%$ as follows:
$\mathrm{V}(\mathrm{ml})=$ body weight $(\mathrm{kg}) \times 80 \mathrm{ml} / \mathrm{kg} \times$ (initial-desired haematocrit)/initial haematocrit.

During PET, blood was withdrawn from a peripheral (radial or posterior tibial)artery through an indwelling catheter, and an equal volume of replacement fluid was given simultaneously through a peripheral vein. ${ }^{4}$ Blood was withdrawn through the umbilical vein only if cannulation of the peripheral arteries was 
Table 1 Demographic characteristics of infants studied (values are *absolute number or tmean (SD)

\begin{tabular}{|c|c|c|}
\hline Characteristics & $\begin{array}{l}\text { Saline group } \\
(n=53)\end{array}$ & $\begin{array}{l}\text { Albumin } \\
\text { group }(n=50)\end{array}$ \\
\hline Male:female ${ }^{\star}$ & $27: 26$ & $26: 24$ \\
\hline Gestation (weeks) $\dagger$ & $38.7(1.7)$ & $38.9(2.3)$ \\
\hline Birth weight $(\mathrm{g}) \dagger$ & $3188(638)$ & $3074(705)$ \\
\hline Postnatal age (hours) $\dagger$ & $2.3(1.7)$ & $2.2(2.2)$ \\
\hline \multicolumn{3}{|l|}{ Maternal complications ${ }^{\star}$ : } \\
\hline Hypertension & 2 & 2 \\
\hline Pre-eclampsia & 4 & 1 \\
\hline Diabetes mellitus & 15 & 9 \\
\hline \multicolumn{3}{|l|}{ Mode of delivery*: } \\
\hline Vaginal & 49 & 45 \\
\hline Abdominal & 4 & 5 \\
\hline \multicolumn{3}{|l|}{ Apgar score at 5 minutes*: } \\
\hline$>4$ & 52 & 50 \\
\hline$\leqslant 4$ & 1 & 0 \\
\hline Pre-PET Hct $\dagger$ & $0.72(0.04)$ & $0.71(0.03)$ \\
\hline \multicolumn{3}{|l|}{ Symptoms and signs ${ }^{\star}$ : } \\
\hline Nil & 8 & 7 \\
\hline Impaired peripheral perfusion & 10 & 10 \\
\hline Neurological signs & 2 & 0 \\
\hline Respiratory distress & 10 & 9 \\
\hline Hypoglycaemia & 32 & 29 \\
\hline
\end{tabular}

unsuccessful. Infusion of replacement fluid was then again through a peripheral vein.

The study was approved by the Clinical Research Ethics Committee of the Chinese University of Hong Kong; and informed consent was obtained from the parents of the infants enrolled.

Vital signs including heart rate, respiratory rate, and transcutaneous oxygen saturation of the infants were monitored continuously during, and for 24 hours after, PET. The efficacy of PET was assessed from the peripheral venous haematocrit, estimated before and at 4 and 24 hours after PET. The immediate drop in haematocrit after PET was also determined on the blood samples withdrawn from the arterial or umbilical venous catheter immediately before and after the procedure. Haematocrit was measured using a standardised technique of centrifugation of blood in a capillary tube at $3000 \mathrm{rpm}$ for 3 minutes. Haemoglobin, serum sodium, and potassium concentrations were determined at the same time points. Throughout their hospital stay, the infants were carefully monitored for complications of polycythaemia, including hyperbilirubinaemia and necrotising enterocolitis.

Table 2 Effect of PET on haematological and biochemical variables (values are mean $(S D)$ )

\begin{tabular}{|c|c|c|c|c|}
\hline & Before PET & $4 h$ after PET & $24 h$ after PET & $\begin{array}{l}\text { P values } \\
(\text { ANOVA })\end{array}$ \\
\hline \multicolumn{5}{|l|}{ Haematocrit: } \\
\hline Saline group & $0.72(0.04)$ & $0.55(0.05)$ & $0.54(0.05)$ & $<0.0019$ \\
\hline Albumin group & $0.71(0.03)$ & $0.54(0.06)$ & $0.54(0.05)$ & $<0.0019$ \\
\hline \multicolumn{5}{|l|}{ Haemoglobin $(\mathrm{g} / \mathrm{l})$ : } \\
\hline Saline group & $218(23)$ & $179(17)$ & $179(16)$ & $<0.0019$ \\
\hline Albumin group & $215(16)$ & $173(20)$ & $173(18)$ & $<0.001$ \\
\hline \multicolumn{5}{|c|}{ Total white cells $\left(\times 10^{9} / l\right)$ : } \\
\hline Saline group & $18.9(5.5)$ & $21.0(5.6)$ & $19.0(6.3)$ & $0.015^{\star}$ \\
\hline Albumin group & $18.7(4.6)$ & $20.9(6.4)$ & $18.9(6.3)$ & $0.006^{\star}$ \\
\hline \multicolumn{5}{|c|}{ Platelet count $\left(\times 10^{9} / \mathrm{l}\right)$ : } \\
\hline Saline group & $238(53)$ & $207(66)$ & $222(69)$ & $0.002 \ddagger$ \\
\hline Albumin group & $238(55)$ & $213(56)$ & $208(61)$ & $<0.001 \dagger$ \\
\hline \multicolumn{5}{|c|}{ Serum [Na] (mmol/l): } \\
\hline Saline group & $136.1(2.9)$ & $136.9(3.6)$ & $137.4(3.4)$ & 0.121 \\
\hline Albumin group & $135.7(3.6)$ & $135.9(3.7)$ & $136.0(4.4)$ & 0.859 \\
\hline \multicolumn{5}{|l|}{ Serum $[K]$ (mmolll): } \\
\hline Saline group & $4.5(0.7)$ & $4.6(0.7)$ & $4.5(0.6)$ & 0.642 \\
\hline Albumin group & $4.3(0.6)$ & $4.4(0.6)$ & $4.4(0.5)$ & 0.434 \\
\hline
\end{tabular}

* Tukey test: $4 \mathrm{~h}>$ pre-PET and $24 \mathrm{~h} \mathrm{P}<0.05$. † Tukey test: pre-PET $>4$ and $24 \mathrm{~h} \mathrm{P}<0.05$. $\ddagger$ Tukey test: pre-PET $>4 \mathrm{~h} \mathrm{P}<0.05$. ๆ Tukey test: pre-PET $>4$ and $24 \mathrm{~h} \mathrm{P}<0.05$.
For data analysis, continuous variables were compared between the groups using the unpaired $t$ test or the Mann-Whitney rank sum test, where appropriate. Repeated measurements in the same group were compared using one way repeated measures analysis of variance (ANOVA), followed by the Tukey test for pairwise comparison when ANOVA showed a significant difference. Proportions were compared using the $\chi^{2}$ test or Fisher's exact test. The sample size was calculated to permit detection of a difference in the reduction of haematocrit by 3\% (SD 5\%). Forty five infants were required in each group to achieve a power of $\geqslant 0.8$ and an $\alpha$ error of not more than 0.05 .

\section{Results}

One hundred and three infants, 53 in the saline group and 50 in the $5 \%$ albumin group, were enrolled. All infants had their umbilical cord clamped immediately after delivery. The two groups were similar in their demographic characteristics, including sex distribution, gestation, birthweight, postnatal age, haematocrit before PET, and the volume of replacement fluid used for PET (table 1).

In both groups PET resulted in a significant immediate reduction in haematocrit of 19.3 (SD 5.7 ) \% and 22.8 (SD 7.0 ) \% of the pre-PET values in the saline and albumin groups, respectively. There was a small but significant difference in the magnitude of haematocrit decrease between the two groups $(P=0.007)$. Changes in haematological and biochemical variables are summarised in table 2. At 4 and 24 hours after PET, both haematocrit and haemoglobin concentrations were significantly lower than the pre-PET values in both groups. Comparison of the two groups showed no significant difference in these variables at the corresponding time points. Both white cell and platelet counts showed significant changes after PET. In both groups the total white cell counts measured at 4 hours were higher than the pre-treatment values, but returned to baseline at 24 hours. In contrast, platelet count at 4 hours was significantly lower than that before PET in both groups. This significant drop in platelet count was also observed at 24 hours after PET in the albumin group. Comparison between the two groups of the magnitude of change in these variables at both 4 and 24 hours after PET showed no sig-

Table 3 Changes in haematocrit, haemoglobin, white cell and platelet count at 4 and 24 hours after PET (as percentage of the pre-PET value): mean (SD)

\begin{tabular}{|c|c|c|c|}
\hline Hours & $\begin{array}{l}\text { Saline group } \\
(\%)\end{array}$ & $\begin{array}{l}\text { Albumin group } \\
(\%)\end{array}$ & $\begin{array}{l}\text { Pvalue } \\
\text { (non-paired } \\
\text { t test) }\end{array}$ \\
\hline \multicolumn{4}{|c|}{ Haematocrit: } \\
\hline 4 & $21.2(8.0)$ & $22.7(9.5)$ & 0.367 \\
\hline 24 & $24.3(6.7)$ & $22.7(9.7)$ & 0.313 \\
\hline \multicolumn{4}{|c|}{ Haemoglobin: } \\
\hline 4 & $16.2(7.5)$ & $18.3(8.0)$ & 0.176 \\
\hline & $16.0(9.5)$ & $18.9(8.7)$ & 0.111 \\
\hline \multicolumn{4}{|c|}{ White cell count: } \\
\hline 4 & $17.3(32.5)$ & $17.0(35.7)$ & 0.975 \\
\hline & $9.0(38.9)$ & $7.3(34.5)$ & 0.824 \\
\hline \multicolumn{4}{|c|}{ Platelet count: } \\
\hline 4 & $14.0(21.7)$ & $9.1(13.4)$ & 0.180 \\
\hline 24 & $8.2(21.6)$ & $13.3(20.8)$ & 0.220 \\
\hline
\end{tabular}


Table 4 Effect of PET on blood pressure and occurrence of hyperbilirubinaemia (values are ${ }^{*}$ mean (SD) or tabsolute number)

\begin{tabular}{|c|c|c|}
\hline & $\begin{array}{l}\text { Saline group } \\
(n=53)\end{array}$ & $\begin{array}{l}\text { Albumin group } \\
(n=50)\end{array}$ \\
\hline \multicolumn{3}{|l|}{ Mean blood pressure $(\mathrm{mm}$} \\
\hline Before PET & $53.7(8.0)$ & $51.0(9.1) \ddagger$ \\
\hline Immediately after PET & $51.0(9.0)$ & $49.5(9.5) \ddagger$ \\
\hline $4 \mathrm{~h}$ after PET & $52.2(7.4)$ & $50.8(7.1) \ddagger$ \\
\hline $24 \mathrm{~h}$ after PET & $52.7(5.9)$ & $52.2(6.9) \ddagger$ \\
\hline $\begin{array}{l}\text { Hyperbilirubinaemia (peak } \\
\text { serum bilirubin } \\
\text { concentration } \geqslant 250\end{array}$ & & \\
\hline$\mu \mathrm{mol} / \mathrm{l}) \dagger$ & $10 \neq \ddagger$ & $7 \neq \ddagger$ \\
\hline
\end{tabular}

One way repeated measures ANOVA: $\uparrow \mathrm{P}=0.141 ; \ddagger$

$\mathrm{P}=0.104$; Fisher's exact test: $\ddagger \mathrm{P}=0.689$.

nificant differences (table 3 ). In both groups PET was not associated with any significant change in serum sodium and potassium concentrations (table 2) or blood pressure (table 4 ) at either 4 or 24 hours. Daily monitoring of serum bilirubin concentration also showed no significant difference between the two groups in the proportion of infants with significant hyperbilirubinaemia (peak serum bilirubin concentration $\geqslant 250 \mu \mathrm{mol} / \mathrm{l}$ ) (table 4$)$. No adverse clinical effects were observed after PET. None of the infants, including those who received PET through the umbilical blood vessels (nine in the isotonic saline group and seven in the albumin group), developed necrotising enterocolitis, feed intolerance, bloody stool, or abdominal distension.

\section{Discussion}

Although polycythaemia is relatively common in neonates, affecting about $4-5 \%$ of full term infants, there are considerable uncertainties about the diagnostic criteria and prognosis of this condition. As a result, the indication for treatment with PET remains controversial..$^{5-9}$ In our unit polycythaemia is diagnosed on a haematocrit of $\geqslant 0.65$. Partial exchange transfusion is carried out in all infants with a value $\geqslant$ 0.70 or, for those with a haematocrit of $0.65-0.69$, when symptoms or signs attributable to circulatory hyperviscosity are present. The replacement fluid used in PET traditionally consists of a colloid solution such as $5 \%$ albumin, fresh frozen plasma, or serum preparation. These solutions are believed to have a greater and more sustained haemodilution effect than crystalloid solutions, because they are retained in the intravascular space for longer by virtue of their higher oncotic pressure. However, in sick infants their protein content may leak into the extravascular compartments, resulting in interstitial and pulmonary oedema.$^{10}$ Moreover, colloid solutions are made of biological products that are associated with potential infection risks. In contrast, crystalloid solutions are free from these complications, and should be the replacement fluids of choice provided their therapeutic efficacy is clinically acceptable.

As far as we are aware, only one study has compared the effects of PET using a crystalloid (Ringer's solution) and a colloid (serum preparation) on polycythaemic neonates. ${ }^{3}$ This study, which showed that the two solutions were equally effective in reducing haematocrit, was limited by the lack of statistical power to detect a small difference because of the relatively small sample size of only 10 infants in each group, and also by the fact that both Ringer's solution and serum preparation are rarely used as replacement fluid for PET. Furthermore, the study did not provide any comparison on the sustained effects of the two solutions on the haematocrit which was measured only up to 4 hours after PET.

The isotonic saline and 5\% albumin used in this study are widely used as replacement fluid for PET and for the treatment of hypotension in neonates, ${ }^{11}$ and for the latter purpose we have shown that they are equally effective. ${ }^{12}$ Our findings show that both solutions had a similar effect in reducing the haematocrit and haemoglobin concentration of polycythaemic infants immediately and up to 24 hours after PET. Although the immediate drop in haematocrit after PET with isotonic saline was statistically smaller than that of albumin, the difference was too small to be of any clinical importance. Subsequent haematocrit at 4 and 24 hours after PET were not significantly different between the two groups. The efficacy of PET may also be reflected indirectly by its effect on serum bilirubin concentration as neonatal hyperbilirubinaemia is a known complication of untreated polycythaemia. In this study PET with the two types of replacement fluid did not result in any significant difference in the occurrence of significant hyperbilirubinaemia.

Some of the haematological changes observed in this study are not readily explained by PET, and the mechanism for their occurrence can only be speculative. The transient increase in total white cell count following PET that was documented 4 hours after the procedure might represent a transient inflammatory response to the intravascular cannulae or the replacement fluid. The small but significant decrease in platelet count after PET might represent a dilutional effect which is commonly observed in infants who have undergone total exchange transfusion. No adverse clinical complication was observed in any of the infants after PET. In neither groups was PET associated with any significant changes in blood pressure or serum sodium and potassium concentrations. None of the infants developed any evidence of intestinal injuries, known complications of polycythaemic infants especially those treated with PET through the umbilical vessels. ${ }^{8}$ The use of peripheral vessels for both blood withdrawal and fluid replacement in this study might have conferred some protection against these complications. We did not measure blood viscosity, a more specific indicator than haematocrit of the effect of PET. In most neonatal units, however, facilities for estimation of blood viscosity are not available and haematocrit remains the most commonly used surrogate marker of the severity of the hyperviscosity syndrome.

1 Wirth FH, Goldberg KE, Lubchenco Lo. Neonatal hyperviscosity: Incidence. Pediatrics 1979; 63:833-6. 2 Gross GP, Hathaway WE, MC Gaughey HR. Hyperviscosity in the neonate. F Pediatr 1973; 82:1004. 
3 Roithmaier A, Arlettaz R, Bauer K, Bucher HU, Kreiger M, Duc G, et al. Randomized controlled trial of Ringer solution versus serum for partial exchange transfusion
natal polycythaemia. Eur $\mathcal{F}$ Pediatr 1995; 154:53-6.

natal polycythaemia. Eur f Pediatr 1995; 154:53-6.
4 Fok TF, So LY, Leung KW, Wong W, Feng CS, Tsang SS. Fok TF, So LY, Leung KW, Wong W, Feng CS, Tsang SS.
Use of peripheral vessels for exchange transfusion. Arch Dis Child 1990;65:676-8.

5 Ramamurthy RS, Brans YW. Neonatal polycythemia: I. Criteria for diagnosis and treatment. Pediatrics 1981;68:16974.

6 Bada HS, Korones SB, Pourcyrous M, Wong SP, Wilson WM 3rd, Kolni HW, et al. Asymptomatic syndrome of polycythemic hyperviscosity: effect of partial plasma
exchange transfusion. $\mathcal{A}$ Pediatr 1992;120:579-85.

7 Bada HS, Korones SB, Kolni HW, Fitch CW, Ford DL, Magill HL, et al. Partial plasma exchange transfusion improves cerebral hemodynamics in symptomatic neonatal polycythemia. Am f Med Sci 1986; 291:157-63.

8 Black VD, Rumack CM, Lubchenco LO, Koops BL. Gastrointestinal injury in polycythemic term infants.
Pediatrics 1985;76:225-31.

9 Goldberg K, Wirth FH, Hathaway WE, Guggenheim MA, Murphy JR, Braithwaite WR, et al. Neonatal hyperviscosity II. Effect of partial plasma exchange transfusion. Pediatrics 1982;69:419-25.

10 Moss GS, Rice CL, Sehgal LR, Gould SA, Rosen AL, Sehgal HL. Use of albumin as a volume expander. In: Hoffman R, Shattil SJ, Furie B, Cohen HS, eds. Haematology basic principles and practice. New York: Churchill Livingstone, 1991:1636-8.

11 Glader BE, Naiman JL. Erythrocyte disorders in Infancy. In: Taeusch HW, Ballard RA, Avery ME, eds. Schaffer and Avery's Diseases of the Newborn. Sixth Edn. Philadelphia: Avery's Diseases of the Newborn.
WB Saunders Co, 1991:822-3.

12 So KW, Fok TF, Ng PC, Wong W, Cheung KL. Randomized controlled trial of the use of colloid or crystalloid in hypotensive preterm infants. Arch Dis Child 1997;76:F43-6. 